\title{
Comparing the Quality of Iodine in Edible Salt in Iranian Households Living in the Southern Province of Khorasan-e-Razavi Using WHO Standards (Years 2010-2015)
}

\author{
Hamed Ramezani Awal Riabi, ${ }^{1}$ Hamid Ramezani Awal Riabi, ${ }^{2}$ Ali Aalami, ${ }^{3}$ \\ Morteza Mohammadzadeh Moghadam, ${ }^{2}$ and Seyed Farzam Mircheraghi ${ }^{4}$ \\ ${ }^{1}$ Faculty of Health, Department of Public Health, Gonabad University of Medical Sciences, Gonabad, Iran \\ ${ }^{2}$ Department of Basic Sciences, Gonabad University of Medical Sciences, Gonabad, Iran \\ ${ }^{3}$ Department of Environmental Health, Gonabad University of Medical Sciences, Gonabad, Iran \\ ${ }^{4}$ Faculty of Medicine, Gonabad University of Medical Sciences, Gonabad, Iran \\ Correspondence should be addressed to Hamid Ramezani Awal Riabi; hamidramezani65@gmail.com
}

Received 25 July 2016; Revised 12 November 2016; Accepted 20 December 2016; Published 27 February 2017

Academic Editor: Jesús Lozano

Copyright (c) 2017 Hamed Ramezani Awal Riabi et al. This is an open access article distributed under the Creative Commons Attribution License, which permits unrestricted use, distribution, and reproduction in any medium, provided the original work is properly cited.

\begin{abstract}
Iodine deficiency disorder among Iranians is a major health-related issue. The aim of this study was to determine iodine concentration in household salt. To sample the iodized salt products, the authors visited all wholesale warehouses of two cities of Bajestan and Gonabad in Khorasan-Razavi, Iran, and randomly purchased three packages of each brand of factory salt distributed through those centers. The sampling procedure was continued over the course of five years (2010-2015). In the 5-year study period, 82 samples of 23 different brands of factory salt were sampled. The most frequent samples were classified into three groups based on their iodine content $(\mathrm{ppm}=\mathrm{mg}$ iodine per kg of salt): under standard limit $(<20 \mathrm{ppm})$; allowable standard limit $(20-50 \mathrm{ppm})$; over standard limit $(>50 \mathrm{ppm})$. The tests showed that $67 \%$ of samples maintained a good level, $26.8 \%$ possessed an acceptable level, and $6 \%$ had unacceptable levels of iodine. Mean and standard deviation of the salt iodine content were 24.7 and 13.7 , respectively. According to the results, the iodine content of samples showed significant differences with international standards (40 ppm), and this highlights the necessity of stricter monitoring of the salt production.
\end{abstract}

\section{Introduction}

The human recognition of goiter dates back to thousands of years ago; however, cretinism is only one hundred years old [1]. The oldest reports about these conditions are from the ancient civilizations of China, India, Greece, and Rome. One of the earliest reports of goiter is the legendary Emperor of China, Shen Nong, where he describes the effects of sea grass in the treatment of this condition. The treatment of goiter with sea grass and seaweeds can also be found in the works of the famous Chinese author Ghe-Khun (317-419 AD) [1].

Iodine deficiency is one of the globally known and spread nutritional disorders and is often cited as the prime preventable cause of mental and physical retardation; hence, control of iodine intake is now considered as one of the most critical tasks of modern medical authorities [2].

A minimum 750 million people around the globe are candidates for iodine deficiency disorders. Thus, nowadays iodine deficiency is considered one of the most communal origins of mental insufficiency in the world. Statistics say that, in 1989 alone, approximately 20 million Iranians suffered from iodine deficiency [3].

Every year, around 38 million children are mentally retarded because of iodine deficiency, where the burden falls on the economy and society [4]. The best strategy for control of iodine deficiency in most countries is iodization of salt, which is considered as one of the most suitable methods to reduce related later expenditure and support economic and 
social development. In case of unavailability of iodized salt, iodine supplements can be administered for sensitive groups [5].

The national research council of Iran has recommended a daily iodine intake of 150 micrograms for adults, plus 25 and 50 micrograms added dose for pregnant and lactating women [6]. According to previously studies, Iran is located along the iodine deficiency belt and extensive national surveys conducted in the early 1980s presented degrees of iodine deficiency in some regions [7]. Iran's iodine supplementation programs for eliminating iodine deficiency disorders began in 1989 and since the adoption of the iodized salt act in 1994, use of iodized factory salt by households has surpassed $90 \%$ [8]. The present law enacted by Iran's national health committee requires factory salt products to maintain $40 \mathrm{ppm}$ iodine in the form of Potassium Iodate [8]. Considering the fact that iodized salt is the most inexpensive and easiest solution for reducing iodine deficiency in Iranian households and keeping in mind the significant reduction of goiter cases in recent years, maintaining the global standard of iodine intake in Iranians via close monitoring and evaluation of salt production and distribution in the market is of great importance, while overlooking this matter of great significance may result in serious consequences [9]. In a study in 2009 conducted on iodized salt production of 14 factories in Khorasan province of Iran, they did not adhere to global iodine standards $(40 \mathrm{ppm})$ in the produce [10]. In a survey of iodine, purity and content of edible salt in insoluble materials available at food shops of Karaj city, results showed that, in the 70 collected samples, $79 \%$ maintained acceptable iodine [11]. In a study in eight cities of the Lorestan province of Iran, 240 samples of 20 brands of marketed edible salt were sampled randomly during April 2014 to March 2015. Iodine concentration was measured via the titration method. Results presented that iodine concentration in $64.59 \%$ of salt samples is acceptable according to WHO standards [12].

Therefore, the aim of this study is to determine iodine concentration in household salt, the coverage of adequately iodized salt, and usefulness of salt as a carrier of iodine in Khorasan-Razavi, Iran, and to offer solutions necessary to resolve the probable problems in this regard.

\section{Materials and Methods}

2.1. Sampling Method. A cross-sectional survey was conducted using a multistage stratified cluster sample of a planned 100 wholesale warehouses and 100 small grocery stores according to geographic maps. This study was conducted over a period of five years (2010-2015). In each instance of sampling, three packages of each brand were randomly sampled; the specifications printed on the packages were logged in the standard inventory of Iran's food and drug administration, and all samples were transferred to the laboratory. To ensure proper sampling, the factory salt sold on the shelves of a number of small grocery stores were also sampled.

Data of this study were obtained using the method recommended by the Department of Food and Drug Administration of the Islamic Republic of Iran and respective ethical considerations were made to preserve the identity of

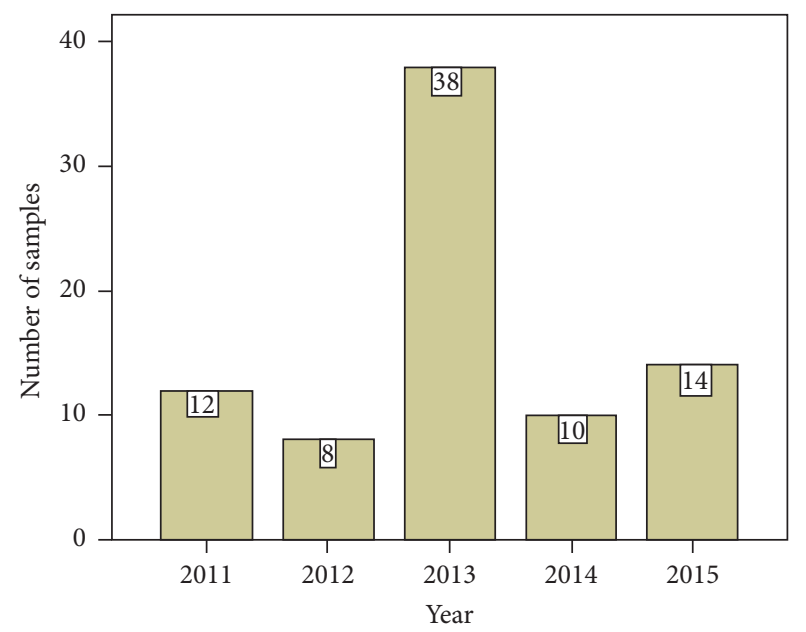

FIGURE 1: Frequency of sampling edible salt per year.

manufacturers and distributors of edible salt. Each brand of salt was given a separate identification code.

2.2. Laboratory Measurement of Iodine in Salt. In the laboratory, all samples were tested via the titration method recommended by the British Pharmacopeia. In accordance with the recommended procedure, 10 grams of salt was taken from each package and transferred to a $50 \mathrm{cc}$ volumetric flask, which was then filled to that volume with distilled water. The resulting solution was then transferred to an Erlenmeyer flask and was stirred repeatedly to obtain a uniform solution. Next, $1 \mathrm{cc}$ of concentrated sulfuric acid and $5 \mathrm{cc}$ of $10 \%$ potassium iodide were added to the solution. The subsequent reaction released the iodine of the salt, turning the color of the resulting product to yellow. The flask was kept out of light for 10 minutes to let the reaction run its course. Then a few drops of starch adhesive were added to the solution. Adding the reagent to the sample produced a dark blue (almost black) color, and the resulting product was titrated by sodium thiosulfate 0.005 normal solution. To calculate the iodine content of the sample, the volume of consumed titer was multiplied by 10.58, giving the iodine concentration in microgram per gram or $\mathrm{ppm}$. The above described procedure was repeated for all samples.

2.3. Statistical Analysis. Statistical analysis was carried out using Chi-square and One-Sample Test using IBM SPSS software V.20 to determine if there were any significant differences among the groups. The significance level was considered at $P<0.05$.

\section{Results}

Over the course of five years, a total of 82 samples of 23 different brands of edible salt were sampled (Figure 1). The most frequently sampled brands were Code 2 (45.1\%). In accordance with recommendations of the Iodine Standards National Committee of Iran, the samples were classified into three groups based on their iodine content $(\mathrm{ppm}=\mathrm{mg}$ iodine 
TABLE 1: Different brands of salt sampling frequencies according to their average gamma iodine values.

\begin{tabular}{|c|c|c|c|c|}
\hline Salt brand code & Frequency & Percentage & Mean iodine/ppm & Mode of iodine/ppm \\
\hline 1 & 1 & 1.2 & 30.4 & 30 \\
\hline 2 & 37 & 45.1 & 27.5 & 22 \\
\hline 3 & 5 & 6.1 & 20.6 & 49 \\
\hline 4 & 2 & 2.4 & 0 & 0 \\
\hline 5 & 5 & 6.1 & 32.4 & 42 \\
\hline 6 & 4 & 4.9 & 25.5 & 34 \\
\hline 7 & 1 & 1.2 & 30.4 & 30 \\
\hline 8 & 1 & 1.2 & 27 & 27 \\
\hline 9 & 3 & 3.7 & 19.3 & 4 \\
\hline 10 & 1 & 1.2 & 3 & 3 \\
\hline 11 & 3 & 3.7 & 22.1 & 14 \\
\hline 12 & 1 & 1.2 & 22 & 22 \\
\hline 13 & 1 & 1.2 & 26 & 26 \\
\hline 14 & 2 & 2.4 & 31 & 31 \\
\hline 15 & 1 & 1.2 & 29.5 & 30 \\
\hline 16 & 2 & 2.4 & 24 & 23 \\
\hline 17 & 2 & 2.4 & 31 & 25 \\
\hline 18 & 1 & 1.2 & 23.3 & 23 \\
\hline 19 & 2 & 2.4 & 31.05 & 28 \\
\hline 20 & 1 & 1.2 & 3 & 3 \\
\hline 21 & 3 & 3.7 & 23.7 & 21 \\
\hline 22 & 2 & 2.4 & 5 & 0 \\
\hline 23 & 1 & 1.2 & 5 & 5 \\
\hline Total & 82 & 100 & 24.7 & 21.3 \\
\hline
\end{tabular}

*ppm: Part per million.

per $\mathrm{kg}$ of salt): under standard limit (<20 ppm); allowable standard limit (20-50 ppm); over standard limit (>50 ppm) [9].

Mean and SD the salt iodine content were 24.7 and 13.7, respectively (Table 1 ).

The products coded as $1,5,7,14,17$, and 19 had good iodine level and those coded as 4, 9, 10, 20, 22, and 23 had an acceptable iodine level. The tests showed that $67 \%$ of samples maintained a good level, $26.8 \%$ had an acceptable level, and $6 \%$ had an unacceptable level of iodine. There was no significant relationship between the samples iodine content and the month during which they were taken $(P=$ 0.300) (Table 2).

There was no significant relationship between the time of sampling and product brands $(P>0.05)$. A large part of the sampling procedure (30\%) was carried out between 2 and 3 months from the date of product of the salt. The average iodine in various salt brands exhibited a significant difference to the extent permitted by the World Health Organization (40 ppm) $(P=0.000)$ (Table 3).

There was also a significant difference between the average iodine contents of different brands $(P=0.000)$ (Table 4$)$.

\section{Discussion}

Based on the findings of this study, it was expected that more salt brands would be a higher percentage of iodine in the
TABLE 2: Monthly salt sampling frequencies and their gamma iodine values.

\begin{tabular}{|c|c|c|c|c|c|}
\hline \multirow{2}{*}{ Valuable } & \multicolumn{3}{|c|}{ \% Iodine/ppm } & \multirow{2}{*}{ Total } & \multirow{2}{*}{$P$ value } \\
\hline & $<20$ & $20-50$ & $>50$ & & \\
\hline \multicolumn{6}{|l|}{ Month } \\
\hline Apr & 6 & 9 & 2 & 17 & \multirow{12}{*}{0.300} \\
\hline May & 5 & 12 & 0 & 17 & \\
\hline Jun & 2 & 4 & 0 & 6 & \\
\hline Jul & 0 & 2 & 0 & 2 & \\
\hline Aug & 1 & 4 & 0 & 5 & \\
\hline Sep & 0 & 5 & 0 & 5 & \\
\hline Oct & 3 & 3 & 0 & 6 & \\
\hline Nov & 0 & 1 & 0 & 1 & \\
\hline Dec & 1 & 7 & 0 & 8 & \\
\hline Jan & 3 & 6 & 0 & 9 & \\
\hline Mar & 1 & 2 & 3 & 5 & \\
\hline Total & 22 & 55 & 5 & 82 & \\
\hline
\end{tabular}

standard of $40 \mathrm{ppm}$, but only $67 \%$ of the samples had good iodine and salt samples with unacceptable levels of iodine were between 6 and $26.8 \%$. Code 3 salt above standard iodine (40 ppm) and Code 22 salt had no iodine. It seems that factors such as failure in adequately monitoring producers of iodized salt have resulted in producers overlooking the importance 
TABLE 3: Average iodine values in salt samples compared to standard iodine values in table salt (ppm).

\begin{tabular}{|c|c|c|c|c|c|c|}
\hline & \multicolumn{6}{|c|}{ Test value $=40$} \\
\hline & \multirow{2}{*}{$t$} & \multirow{2}{*}{ df } & \multirow{2}{*}{$P$ value } & \multirow{2}{*}{ Mean } & \multicolumn{2}{|c|}{$95 \% \mathrm{CI}$} \\
\hline & & & & & $\operatorname{Max}$ & Min \\
\hline Iodine & 10.099 & 81 & 0.000 & -15.302 & -18.32 & -12.29 \\
\hline
\end{tabular}

CI: confidence interval; df: degrees of freedom.

TABLE 4: Comparing average iodine values in salt samples (ppm).

\begin{tabular}{|c|c|c|c|c|c|c|}
\hline \multicolumn{7}{|c|}{ One-Sample Test } \\
\hline & \multicolumn{6}{|c|}{ Test value $=0$} \\
\hline & \multirow{2}{*}{$t$} & \multirow{2}{*}{$\mathrm{df}$} & \multirow{2}{*}{$P$ value } & \multirow{2}{*}{ Mean difference } & \multicolumn{2}{|c|}{$95 \% \mathrm{CI}$} \\
\hline & & & & & Max & Min \\
\hline Iodine & 16.299 & 81 & 0.000 & 24.698 & 21.68 & 27.71 \\
\hline
\end{tabular}

ppm $=$ part per million .

of iodized salt quality that will ultimately lead to higher risks of goiter among the population. Other factors such as improper storage and maintenance of salt in food shops, transportation of salt and high temperatures, and humidity can lead to destroying iodine in salt. According to recent data from the University of Illinois, Chicago, an improvement between 2003 and 2011 was made when the number of iodine deficient countries decreased from 54 to 32 and the countries that have adequate intake of iodine increased from 67 to 105. However, globally 241 million of school age children are estimated to have poor iodine intake [8]. Iodine deficiency remains a major public health concern in many countries, including some European countries [13].

Until two decades ago, Iran was one of the countries suffering from severe iodine deficiency [7]. The first national survey of iodine disorders conducted in 1989 reported 30\% to $80 \%$ prevalence of goiter among schoolchildren in most provinces. This led to adoption of a law (1994) mandating the production of iodized salt for household consumption. The last goiter survey conducted in Iran (2007) reported a prevalence of $5.7 \%$ [14]. A study on the iodine content of factory salt used in Khorasan-e-Razavi province reported that $45 \%$ of its samples had $30-50$ ppm of iodine, but in the present study, only $25.6 \%$ of the samples exhibited this level of iodine content [14].

In the third monitoring of iodized salt in Iran (2001), mean \pm SD (95\% confidence interval) and median of produced iodine 297 salt were 33.2-13.4 and 32.8 ppm, respectively; and in 1996, these values were measured as $33.8 \pm 13.2$ and 33.9 ppm, respectively [15].

The mean and standard deviation obtained in the present study have are in good agreement with the results of the 2007 survey, where mean and standard deviation of iodine content have been reported as 23.2 and $13.8 \mathrm{ppm}$. The mean \pm SD and the median (interquartile range) of iodine content of salts consumed by households in south Tehran were obtained as $12.7 \pm 14.7$ ppm and 3.2 (1.6-25.9) ppm, respectively [16].

In a study in eight cities of the Lorestan province of Iran, 240 samples of 20 brands of marketed edible salt were sampled randomly during April 2014 to March 2015. Iodine concentration was measured via the titration method. Results presented that iodine concentration in $64.59 \%$ of salt samples is acceptable according to WHO standards [12].

In a study by Mohammadi et al. in Bushehr province, Iran, from a total of 54 samples, 55\% of iodine levels were at an acceptable level, and in $45 \%$ of the samples, iodine levels were outside the acceptable range and $34 \%$ were less than the acceptable level (less than $30 \mathrm{ppm}$ ), and $11 \%$ were above the maximum acceptable level (50 ppm) [9].

Temperature and light can affect the quality of iodine in salt, so we expected to observe a difference between the iodine contents of samples taken in warm months and cold months. However, the absence of such difference indicates that wholesale warehouses and grocery stores observe the standard salt storage conditions; thus, inadequacy of iodine content should be attributed either to substandard production or to lack of proper attention to temperature, light, and humidity conditions during transportation.

In our study, six brands of table salt had an iodine level of 30-50 ppm and six brands had an iodine level of less than $20 \mathrm{ppm}$. A study on the iodine content of factory salts produced in Khorasan province reported that, of 14 different factories producing iodized salt, the iodine content of eight factories was within the acceptable range of 30$50 \mathrm{ppm}$; nonetheless, the products of the other six factories were substandard [17].

The study of Mehdinia et al. (2005) on factory salt consumed in Semnan province has also reported that, of 16 brands, 10 had substandard iodine levels [18].

A study conducted in 2000 by Mohammadi et al. examined the iodine content of iodized and generic salt consumed by residents of Bushehr and reported that $89 \%$ of the iodized salts had substandard iodine levels, and $100 \%$ of generic salts had an insignificant level of iodine [9].

Mohammadi et al. reported that the median level of iodine in salt was $23.5 \mathrm{ppm}$ (1995) and $30.0 \mathrm{ppm}$ (2005). A total 32.5 and 2.8 percent of salts had an iodine content of 5-20 ppm and the consumption rates of qualified iodized salt 
(20-50 ppm) in 1995 and 2005 were 59.9 and 96.6 percent, respectively, reflecting the fact that the quality of iodized salt has improved significantly [9].

In a study in China, 108 salt samples were randomly obtained from different supermarkets of different districts. The distribution of iodine was $20.0 \sim 37.8 \mathrm{mg} / \mathrm{kg}$ and iodine concentration in salt was $27.9 \pm 4.33 \mathrm{mg} / \mathrm{kg}$ [19].

One of the limitations of the present study was the absence of an assessment on the iodine content of salts bought and stored by households. The conditions in which salt is stored can have an important impact on its iodine content and can potentially nullify all the efforts taken to maintain standard iodine levels throughout production and distribution; the manner in which salt is used for cooking is another potentially important aspect of this discussion (the loss of iodine content during cooking is estimated at about $20 \%$ ). The lack of direct access to the production process of the salts sampled in this study prevented the authors from comparing the iodine content of the distributed product with those still in the production line. Comparing the results of national surveys conducted in 1996, 2001, and 2007 shows that iodine intake of the Iranian population, which is the main index of iodine-related nutritional status, has been in the acceptable range of $20-40 \mathrm{ppm}$ in both the second and third national surveys [13]. The study of Azizi et al. shows that reduced median of urinary iodine during this period could be attributed to environmental and dietary factors such as poor salt storage methods or excessive use of microwave ovens [15].

In a study, 13 brands of iodized salt of Kashan's shops were sampled during 2010, from which eight brands (61.53\%) had acceptable ranges (30-50 ppm) and five brands (38.46\%) were out of acceptable ranges [20].

A study carried out in New Delhi, India, showed that there was around $31 \%$ iodine loss from iodized salt because of exposure to direct sunlight [21]. A similar study carried out in London, UK, also designated that the same factor, direct sunlight, was linked to loss of iodine levels in salt [22]. This may be of the results of heat on iodine content. Furthermore, another study in Kazakhstan revealed that salt iodized slowly with iodine loses its iodine content when exposed to direct sunlight [23]. A study in Colombia presented that the effect of longer storage beyond two months intensified iodine loss from salt because of various environmental conditions during storage and distribution [24].

\section{Conclusion}

According to the results, the iodine content of samples showed significant differences with international standards (40 ppm), and this highlights the necessity of stricter monitoring of the salt production industry and educating distributors, retailers, and households about the proper conditions of salt storage. Moreover, Iran is currently considered as an iodine-deficiency-free country, but the salt sold and consumed in Southern parts of Khorasan-Razavi province shows moderate levels of iodine deficiency. These findings highlight the necessity of stricter supervision and monitoring of all entities involved in the production and distribution of iodized salt to ensure proper and uniform iodine supplementation for all parts of the country and thereby counter the risk of reemergence of iodine deficiency. The annual survey of students' urinary iodine should also be pushed into the national health agenda.

\section{Competing Interests}

The authors declare that they have no competing interests.

\section{References}

[1] P. Langer, "The history of goiter," in Endemic Goiter, WHO Monograph Series, pp. 9-25, WHO, Geneva, Switzerland, 1960.

[2] P. Nazeri, P. Mirmiran, H. Delshad, M. Hedayati, and F. Azizi, "Evaluation of urinary iodine concentration and iodine content of households salt in South of Tehran," Iranian Journal of Endocrinology and Metabolism, vol. 12, no. 3, pp. 294-319, 2010.

[3] A. Aminorroaya, M. Amini, and S. Hovsepian, "Prevalence of goitre in Isfahan, Iran, fifteen years after initiation of universal salt iodization," Journal of Health, Population and Nutrition, vol. 28, no. 4, pp. 351-358, 2010.

[4] United Nations Children's Fund, Sustainable Elimination of Iodine Deficiency: Progress Since the 1990 World Summit for Children, United Nations Children's Fund, New York, NY, USA, 2008.

[5] M. B. Zimmermann, P. L. Jooste, and C. S. Pandav, "Iodinedeficiency disorders," The Lancet, vol. 372, no. 9645, pp. 12511262, 2008.

[6] F. Azizi, M. Kimiagar, A. A. Ghazi, and M. Nafarabadi, "The effects of iodized oil injection in eu- and hypothyroid iodine deficient girls," Journal of Endocrinological Investigation, vol. 20, no. 1, pp. 18-23, 1997.

[7] M. Mardani, F. Gholaami, P. Rezapour, and F. Ebrahimzadeh, "The prevalence of endemic goiter and its relationship to urine iodine in primary school age children in Khoramabad," Journal of Health Sciences and Surveillance System, vol. 3, no. 2, pp. 7175, 2015.

[8] F. E. Azizi, H. Delshad, L. Mehran et al., "Marked reduction in goiter prevalence and eventual normalization of urinary iodine concentrations in Iranian schoolchildren, 10 years after universal salt iodination," Iranian Journal of Endocrinology and Metabolism, vol. 10, no. 3, pp. 191-203, 2008.

[9] M. M. Mohammadi, R. Shirazi, B. Ghafarian, and M. Mohammadi, "The amount of iodine in edible salt fortified with iodine and salt is not rich in Bushehr in 2000," Southern Medical Journal, vol. 3, no. 107, pp. 2-11, 2000.

[10] M. Hassanzadeh Khayat and A. Jalali Moghadam, "Evaluation of Iodine Content of iodized produced in Khorasan," Iranian Journal of Basic Medical Sciences, vol. 2, no. 3, pp. 146-151, 1999.

[11] K. Akhavan Siahkoli, M. Jafarinia, M. Rafi, M. Zarabi, and A. Afshar, "Survey of iodine concentration, purity and content of edible salt is insoluble materials available in grocery stores in Karaj," in Proceedings of the 16th National Congress on Environmental Health, Tabriz, Iran, October 2012.

[12] R. Sepahvand, M. Hatamikia, H. Hassanzadazar et al., "Iodine concentration in iodized salts marketed in Lorestan Province, West of Iran," Journal of Chemical Health Risks, vol. 6, no. 2, 2016.

[13] WHO, UNICEF, and ICCIDD, Recommended Iodine Levels in Salt and Guidelines for Monitoring Their Adequacy and Effectiveness, WHO, 1996. 
[14] H. Delshad, A. Amouzgar, P. Mirmiran, and F. Azizi, "Eighteen years of universal salt iodization in Iran; the fourth national survey of goiter prevalence and urinary iodine excretion of schoolchildren (2007-2008)," Iranian Journal of Endocrinology and Metabolism, vol. 15, no. 1, pp. 21-32, 2013.

[15] F. Azizi, L. Mehran, R. Sheikholeslam et al., "Sustainability of a well-monitored salt iodization program in Iran: marked reduction in goiter prevalence and eventual normalization of urinary iodine concentrations without alteration in iodine content of salt," Journal of Endocrinological Investigation, vol. 31, no. 5, pp. 422-431, 2008.

[16] P. Nazeri, P. Mirmiran, Y. Mehrabi, M. Hedayati, H. Delshad, and F. Azizi, "Evaluation of iodine nutritional status in Tehran, Iran: Iodine deficiency within iodine sufficiency," Thyroid, vol. 20, no. 12, pp. 1399-1406, 2010.

[17] World Health Organization, UNICEF, and International Council for Control of Iodine Deficiency Disorders, Recommended Iodine Levels in Salt and Guidelines for Monitoring Their Adequacy and Effectiveness, World Health Organization, Geneva, Switzerland, 1996.

[18] S. M. Mehdinia, H. R. Nasehinia, R. Gharib-Bolok, R. Azizi, and M. Rezai, "A Survey of iodine concentration in the iodine salts distributed in the province of Semnan in autumn 2004," Koomesh, vol. 6, no. 4, pp. 285-290, 2005.

[19] Y. Wang, Z. Zhang, P. Ge, Y. Wang, and S. Wang, "Iodine deficiency disorders after a decade of universal salt iodization in a severe iodine deficiency region in China," Indian Journal of Medical Research, vol. 130, no. 4, pp. 413-417, 2009.

[20] R. Dehghani, I. Zarghi, T. Hajijafari, M. Falahnia, and M. Hosseni, "Investigation into level of iodine in market iodized salt in Kashan, 2010," Journal of North Khorasan University of Medical Sciences, vol. 5, no. 3, pp. 593-598, 2013.

[21] K. S. Prakash and D. Nayar, "Study of some factors influencing losses of iodine from iodized salt," Indian Journal of Maternal and Child Health, vol. 9, no. 1, pp. 46-47, 1998.

[22] F. C. Kelly, "Studies on the stability of iodine compounds in iodized salt," Bulletin of the World Health Organization, vol. 9, no. 2, pp. 217-230, 1953.

[23] M. B. Zimmermann, "Assessing iodine status and monitoring progress of iodized salt programs," Journal of Nutrition, vol. 134, no. 7, pp. 1673-1677, 2004.

[24] G.-Y. Wang, R.-H. Zhou, Z. Wang, L. Shi, and M. Sun, "Effects of storage and cooking on the iodine content in iodized salt and study on monitoring iodine content in iodized salt," Biomedical and Environmental Sciences, vol. 12, pp. 1-9, 1999. 

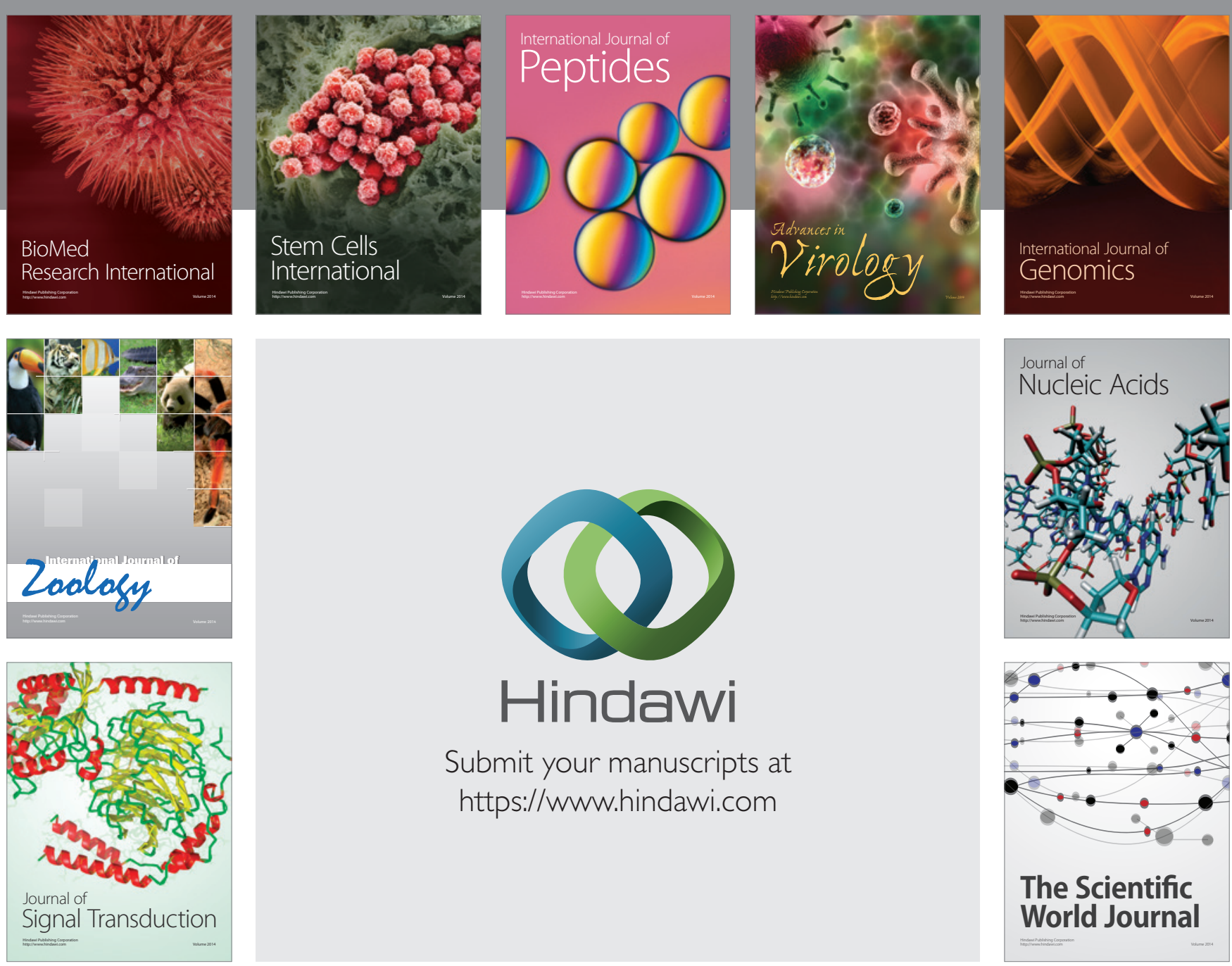

Submit your manuscripts at

https://www.hindawi.com
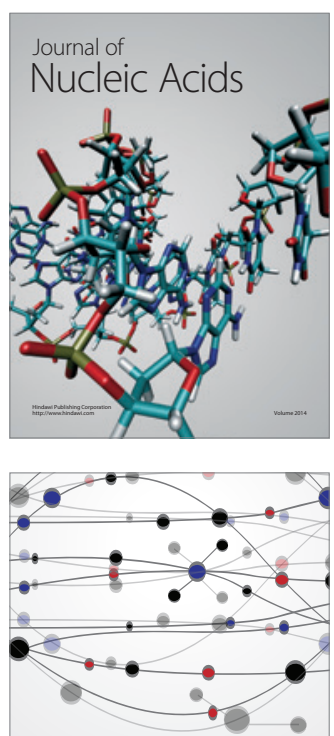

The Scientific World Journal
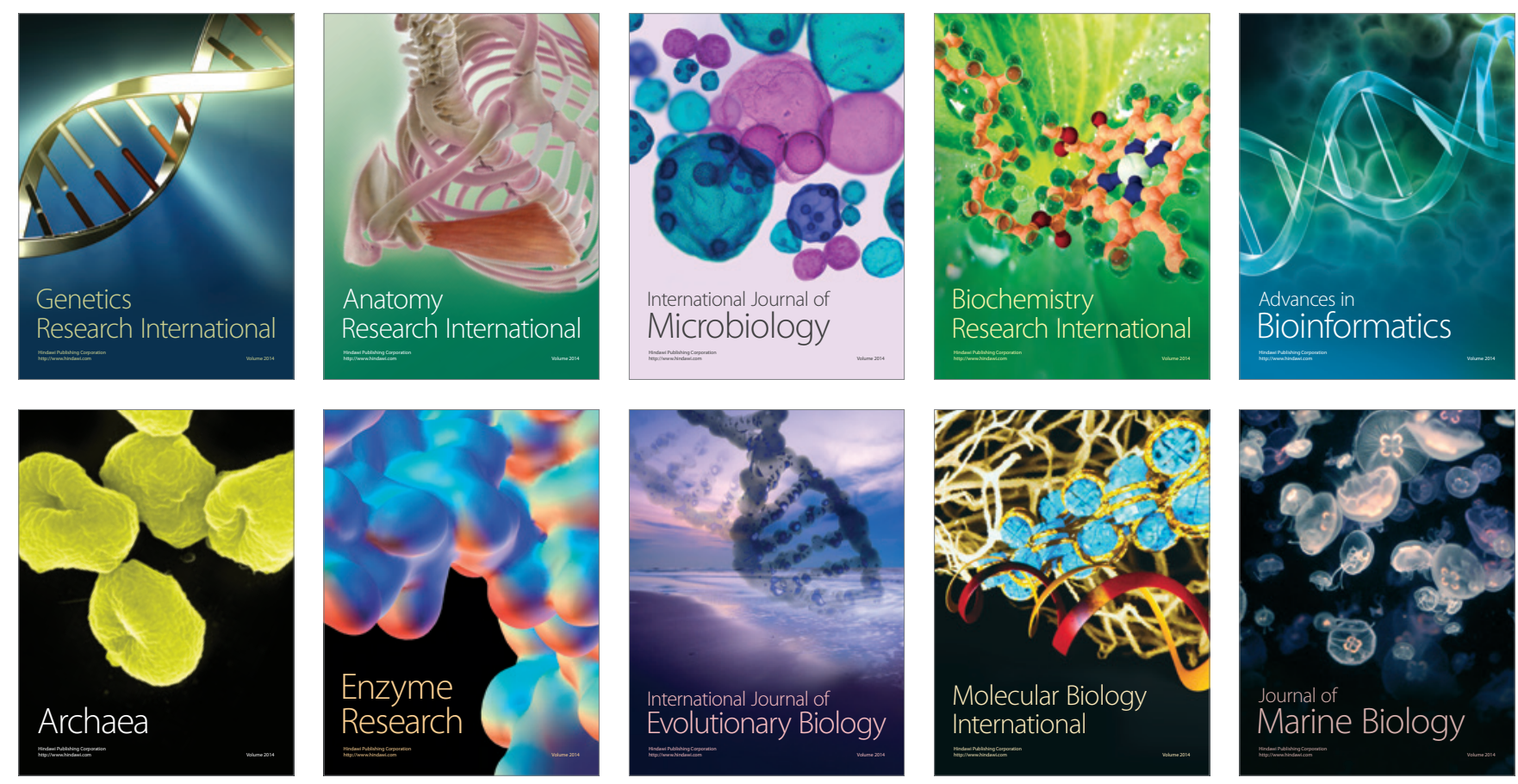